\title{
Persistencia de Epónimos en Terminologia Histologica
}

\author{
Eponyms Persistence in Terminologia Histologica
}

\author{
Ignacio Roa ${ }^{*, * * * * *}$; Bélgica Vásquez ${ }^{* * * * *} \&$ Manuel Contreras ${ }^{* * * * *}$
}

ROA, I.; VÁSQUEZ, B. \& CONTRERAS, M. Persistencia de epónimos en Terminologia histologica. Int. J. Morphol., 34(4):1245$1252,2016$.

RESUMEN: El uso de epónimos aún es una práctica frecuentemente utilizada entre médicos clínicos y académicos para referirse a las distintas estructuras en histología. A pesar de los esfuerzos por parte de la comunidad morfológica por desarraigarlos del lenguaje médico, hoy en día se encuentran, inclusive presentes en Terminologia Histologica, tal como en los casos de Schannocytus (H2.00.06.2.02003) referente a la Célula de Schwann; Complexus golgiensis (H1 .00.01.3.0146) referente al Aparato de Golgi, Cellula panethensis (H3.04.03.0.00017) referente a la Célula de Paneth, y Neuron purkinjense (H3.11.03.4.01015) referente a la Neurona de Purkinje, que aluden a los investigadores Theodor Schwann, Camillo Golgi, Joseph Paneth y Jan Evangelista Purkinje, respectivamente. El objetivo del presente estudio fue realizar un análisis de los términos antes nombrados desde un punto de vista lingüístico y proponer nuevas denominaciones, siguiendo los parámetros establecidos en la Terminología, en la cual los nombres de las estructuras deben tener un valor informativo, estar escritos en latín como lengua base y eliminar el uso de los epónimos. Los términos analizados, se refieren a nombres de células u organelos frecuentemente utilizados en textos educativos, sin embargo, son poco descriptivos, muchos de ellos con raíces netamente griegas y otros neologismos, cuyas denominaciones, por consenso y en honor a investigadores connotados han perdurado en el tiempo. Proponemos modificaciones con respecto a su denominación, así como a sus derivados, utilizando términos procedentes del latín. En resumen, pretendemos que con estos antecedentes iniciales puedan entregarse argumentos que permitan seguir unificando criterios y que ellos puedan ser considerados por los expertos que conforman el Programa Federativo Internacional de Terminología Anatómica y, como bien se señala, permitir el establecimiento de diálogo con los miembros de la Federación Internacional de Asociaciones de Anatomistas e ir mejorando la comunicación científica entre los diferentes actores de las ciencias morfológicas.

PALABRAS CLAVE: Schannocytus; Célula de Schwann; Complexus golgiensis; Aparato de Golgi; Cellula panethensis; Célula de Paneth; Neuron purkinjense; Neurona de Purkinje; Terminologia Histologica; Epónimos.

\section{INTRODUCCIÓN}

El uso de epónimos es una práctica frecuente entre los clínicos y académicos para nombrar las estructuras en el área médica (Goic, 2009). Pese a los esfuerzos, tanto en Terminologia Anatomica (TA), Histologica (TH) y Embryologica (TE), como de la comunidad morfológica por desarraigarlos del lenguaje médico (Vásquez \& del Sol, 2015), estos no han permeado a todos de igual manera, ya que aún es posible encontrar el uso de epónimos en textos educativos y publicaciones científicas, lo que dificulta aún más dejar de usarlos (Duque-Parra et al., 2006; Jiménez-Gutiérrez, 2009; Cruz Gutiérrez et al., 2010).

De acuerdo con lo planteado por la propia terminología, el uso de epónimos muchas veces es poco descriptivo, no favorece el entendimiento y ubicación de las estructuras por parte de los estudiantes y clínicos (González-López, 2010; Duque Parra et al., 2014). En este contexto, al momento de discutir la terminología morfológica internacional, la Federación Internacional de Asociaciones de Anatomistas (IFAA) estableció una serie de indicaciones y sugerencias con la finalidad de regular y normalizar las denominaciones de las estructuras morfológicas. Así, se estableció que: casi todas las estructuras morfológicas se denominen con una sola palabra, el lenguaje empleado sea el latín, se describa el elemento de la forma más fiel a los principios de la geometría y la forma, el término concentre la información y descripción de la estructura, se eliminen las eponimias y el término sea congruente, es decir, que si se aceptan sus derivados se acep-

Unidad de Morfología, Departamento de Ciencias Básicas Biomédicas, Facultad de Ciencias de la Salud, Universidad de Talca, Chile.

** Programa de Doctorado en Ciencias Morfológicas, Facultad de Medicina, Universidad de La Frontera, Temuco, Chile.

**** Becario CONICYT-PCHA/Doctorado Nacional/2015-21150235.

***** Universidad de Tarapacá, Arica, Chile

****** Facultad de Filosofía y Humanidades, Instituto de Lingüística y Literatura, Universidad Austral de Chile, Valdivia, Chile. 
te la palabra primitiva que dio origen a aquellos derivados (Losardo et al., 2010). En cuanto a la denominación de las estructuras morfológicas, diversos autores señalan que se deben respetar las raíces latinas, griegas y árabes y también que se consideren las traducciones aceptadas por las reglas de la linguística de los idiomas oficiales (Jiménez-Gutiérrez; Cruz Gutiérrez et al.; Salgado \& Trujillo, 2010; Mejías Stuven, 2012).

Pese a lo señalado anteriormente, de manera paradójica los epónimos aún se encuentran presentes, no sólo en textos científicos y no científicos, sino también en las distintas terminologías (Whitworth, 2007; Vásquez \& del Sol, 2014; Roa \& del Sol, 2015). Ejemplo de ello, en TH, se pueden observar los términos Schawnnocytus (H2.00.06.2.02003) referente a la Célula de Schwann; Complexus golgiensis (H1.00.01.3.0146) referente al Aparato de Golgi, Cellula panethensis (H3.04.03.0.00017) referente a la Célula de Paneth y Neuron purkinjense (H3.11.03.4.01015) referente a la Neurona de Purkinje (FICAT, 2008).

Schwannocytus o Neurolemmocytus (H2.00.06.2.02003) (FICAT) se refiere al Schwannocito (Célula de Schwann) o Neurilemocito, célula encargada de mielinizar los axones, dar la orientación direccional de las neuronas y eliminar los restos celulares en el sistema nervioso periférico (Bhatheja \& Field, 2006; Sango \& Yamauchi, 2014). Esta célula es llamada así en honor al fisiólogo alemán Theodor Schwann, (1810-1882) cofundador de la histología moderna, el cual definió a la célula como la unidad básica de la estructura de los animales (Kosinski, 2004). Igual situación sucede con el término Complexux golgiensis o Apparatus golgiensis (H1.00.01.3.0146) (FICAT), que se refiere al Aparato de Golgi, organelo celular parte del sistema endomembranoso que es el encargado de empaquetar proteínas en vesículas unidas a la membrana dentro de la célula antes que sean enviadas a su destino (Alberts et al., 2015); fue nombrado en honor al médico, biólogo, patólogo, científico y premio Nobel italiano, Camillo Golgi (1843-1926) quien lo describió en 1898 (Mazzarello et al., 2009). Otro de los términos es el referido a Cellula panethensis o Exocrinocytus um granulis acidophilis (H3 .04.03.0.00017) (FICAT), el que se refiere a las células de Paneth, ubicadas en las criptas del intestino delgado, cuya función antimicrobiana radica en la presencia de gránulos acidófilos citoplasmáticos (Zhang \& Liu, 2016); fue descrita por primera vez, junto con las otras células del epitelio intestinal, en 1872 por el anatomista alemán, histólogo y antropólogo Gustav Albert Schwalbe (1844-1916), sin embargo, fueron nombrados después por el histólogo y fisiólogo austríaco Joseph Paneth (1857-1890), quien realizó un análisis morfológico detallado de la célula en 1888 (Bykov, 2014). Por último el término Neuron purkinjense (H3.11.03.4.01015) (FICAT), referente a la Neurona de Purkinje, células GABAérgicas ubicadas en la corteza cerebelar (Kandel et al., 2001), en honor al fisiólogo checo y uno de los padres de la histología moderna Jan Evangelista Purkyně (Purkinje) (1787-1869) (Noguera-Palau, 2008).

Las evidencias muestran que aún es necesario revisar y discutir las distintas terminologías con la finalidad de armonizar las denominaciones que presentan discrepancias. Por tanto, el objetivo del presente estudio fue realizar un análisis de los términos antes nombrados desde un punto de vista lingüístico y proponer nuevas denominaciones latinas, siguiendo los parámetros establecidos en la IFAA en la que se señala que los nombres de las estructuras deben tener un valor informativo, estar escritos en latín como lengua base y no deben ser usados los epónimos.

\section{ANALISIS Y PROPUESTA}

\section{Schwannocytus o Neurolemmocytus}

El término Schwannocito, del epónimo Schwann y del sufijo -cito, de kyto- xv́ científico, "célula". En griego originalmente tenía como significado "recipiente", aunque el uso de este lexema con el nuevo significado procede del latín cellula "celdilla". El latín lo adquirió a partir del descubrimiento de las células del corcho de Robert Hooke en 1665, a las que llamó en inglés "cell" debido a la similitud con las celdas de un panal. Su uso es bastante reciente, sólo a partir de 1838 (Cortés \& Ureña, 2011). Por otra parte, Neurilema se refiere a un término histológico concerniente al tejido que envuelve una fibra nerviosa, conocido también como vaina de Schwann. Derivado del término francés névrilème [neur(o)- vعv̂oov en griego "nervio", en griego científico "sistema nervioso"

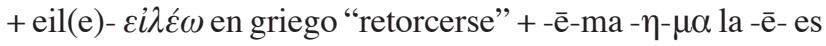
un infijo verbal que indica proceso y el sufijo -ma, indica resultado]. Por lo tanto, la lengua base de este término es el griego, siendo además un neologismo del siglo XIX, acuñado en 1801 en francés por Xavier Bichat, a partir de "eílēma"

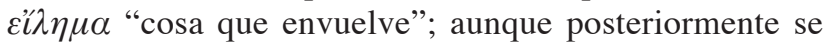
interpretó que era compuesto de lémma $\lambda \varepsilon ́ \mu \mu \alpha$ "peladura", “membrana fina” (Cortés \& Ureña).

Proponemos el término Célula de envoltura nerviosa (Cellula involturae nervosae), del latín Cellula, de cella "recinto cubierto" o "celda de panal" + -ula $(m)$ del latín "pequeño"; involtūra, participio futuro de involvō-vere, traducido [in+volvo] "para envolver, cubierta (con un medio circundante)" y del adjetivo nervosus - - -um, del griego

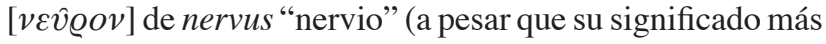
apropiado es tendón o músculo) + -osus. Otro término podría ser Célula de envoltura axonal (Cellula involturae axonis),

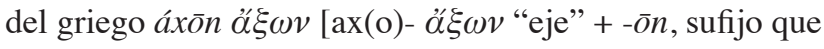


forma el sustantivo]. La lengua base del término es griego, reintroducida con cambio de significado y documentada en 1899 en inglés. Si bien es construida en base al griego expresa de mejor manera la función de la célula: envolver el axón (proyección larga y delgada de una neurona a través de la cual viaja el impulso nervioso de forma unidireccional, desde el cuerpo neuronal hacia otras células) (Cortés \& Ureña) (Tabla I).

\section{Complexus golgiensis o Apparatus golgiensis}

El término "complejo", del latín complexus < complector-complecti, traducido "enlazar"; permite hacer referencia a un conjunto o unión de dos o más cosas que constituyen una unidad (RAE, 2013). Por su parte, el término golgiensis, se encuentra compuesto por Golgi (epónimo) + sufijo -ensis que indica el genitivo (el caso genitivo indica, entre otras características, pertenencia, origen, propiedad, cualidad, autor) de tercera declinación. Según el Diccionario médico-biológico, histórico y etimológico, el término "aparato" se refiere a un conjunto de órganos y estructuras que actúan en combinación para realizar una función, tales como, los aparatos circulatorio, respiratorio, digestivo, reproductor o genital, urinario, lagrimal, yuxtaglomerular, etc. Deriva del latín antiguo apparātus [apparo + -tus], reintroducido y documentado en 1550 en latín renacentista. En latín clásico significa "conjunto de cosas dispuestas con una finalidad"; se especializó después en anatomía, así en inglés en 1718 (Cortés Gabaudan \& Ureña Bracero).

Proponemos la denominación Aparato cisternal (Apparatus cisternalis) del latín apparātu (supra) y latín cisterna,ae [< cista; como en caverna] "tanque subterráneo o hundidos para el almacenamiento de agua" + sufijo adjetival -alis (Glare, 1968). Esta denominación no usa el epónimo Golgi y además, sus términos son más descriptivos desde el punto de vista funcional (Tabla II).

\section{Cellula panethensis o Exocrinocytus granulis acidophilis}

El término Cellula panethensis proviene de "célula", que se refiere a la unidad fundamental de los organismos vivos capaz de dividirse y de tener un metabolismo independiente, constituida básicamente por un genoma inmerso en un citoplasma rodeado por una membrana lipídica; puede vivir como una entidad unicelular, o bien formar parte de un organismo pluricelular. Como se mencionó anteriormente, Cellula, proviene del latín cella + diminutivo -ula. Es un término que tiene como lengua base el latín antiguo con cambio de significado. Su nuevo significado fue acuñado en 1665 por el inglés Robert Hooke, y aunque aparece en latín clásico se difunde sobre todo en latín tardío y medieval como "pequeña habitación" o "celdilla"; se supone que dicho científico fue el primero que usó el término para lo que hoy llamamos células (inglés cell < latín cella) al aplicar el microscopio a tejidos orgánicos y parecerle que eran celdas de panal; en español o francés no se documenta hasta el siglo XIX y, a diferencia del inglés, se usó a partir del diminutivo latino, que era la forma habitual -sermo cotidianus - de referencia en la lengua hablada o latín vulgar (confer $=$ refiérase a en Appendix Probi los casos de latín clásico auris - latín vulgar auricula, oricla $>$ español oreja; latín clásico musivum - latín vulgar museum $>$ español museo). Por su parte el término panethensis, se encuentra compuesto por Paneth (epónimo) + sufijo -ensis del genitivo de tercera declinación.

Tabla I. Análisis del término Schwannocytus o Neurolemmocytus presente en Terminologia Histologica y propuesta de nuevo término latino.

\begin{tabular}{|c|c|c|c|c|c|c|}
\hline $\begin{array}{l}\text { Terminologia } \\
\text { Histologica }\end{array}$ & $\begin{array}{l}\text { Nombre } \\
\text { Común }\end{array}$ & Descripción & Origen & $\begin{array}{l}\text { Propuesta } \\
\text { latín }\end{array}$ & $\begin{array}{l}\text { Propuesta } \\
\text { español }\end{array}$ & Origen \\
\hline $\begin{array}{l}\text { Schwannocytus } \\
\text { H2.00.06.2.02003 }\end{array}$ & $\begin{array}{l}\text { Célula de } \\
\text { Schwann }\end{array}$ & $\begin{array}{l}\text { Célula encargada } \\
\text { de mielinizar } \\
\text { y orientar } \\
\text { direccionalmente } \\
\text { los axones en el } \\
\text { SNP. }\end{array}$ & $\begin{array}{l}\text { Epónimo Schwann } \\
\text { + cito [kyto- } x v i \tau o \varsigma] \\
\text { griego científico: } \\
\text { "célula", "recipiente". }\end{array}$ & $\begin{array}{l}\text { Cellula } \\
\text { involvi } \\
\text { nervosa }\end{array}$ & $\begin{array}{l}\text { Célula de } \\
\text { envoltura } \\
\text { nerviosa }\end{array}$ & 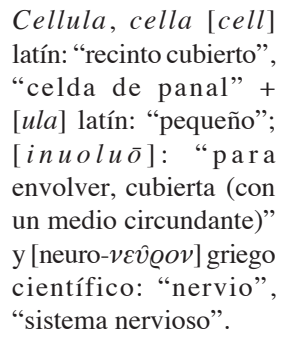 \\
\hline $\begin{array}{l}\text { Neurolemmocytus } \\
\text { H2.00.06.2.02003 }\end{array}$ & & & 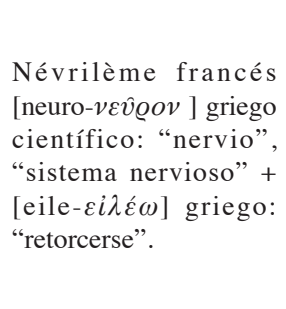 & $\begin{array}{l}\text { Cellula } \\
\text { involvi } \\
\text { axonis }\end{array}$ & $\begin{array}{l}\text { Célula de } \\
\text { envoltura } \\
\text { axonal }\end{array}$ & $\begin{array}{l}\text { Cellula, cella [cell] } \\
\text { latín: "recinto cubierto", } \\
\text { "celda de panal" + } \\
\text { [ula] latín: "pequeño", } \\
\text { [inuoluō]: "Para } \\
\text { envolver, cubierta (con } \\
\text { un medio circundante)" } \\
\text { y áxōn [ } \alpha \hat{\xi} \omega v \text { axo] } \\
\text { griego: "eje". }\end{array}$ \\
\hline
\end{tabular}


Tabla II. Análisis del término Complexux golgiensis o Apparatus golgiensis presente en Terminologia Histologica y propuesta de un nuevo término latino.

\begin{tabular}{|c|c|c|c|c|c|c|}
\hline $\begin{array}{l}\text { Terminologia } \\
\text { Histologica }\end{array}$ & $\begin{array}{l}\text { Nombre } \\
\text { Común }\end{array}$ & Descripción & Origen & $\begin{array}{l}\text { Propuesta } \\
\text { latín }\end{array}$ & $\begin{array}{l}\text { Propuesta } \\
\text { español }\end{array}$ & Origen \\
\hline $\begin{array}{l}\text { Complexus } \\
\text { golgiensis } \\
\text { H1.00.01.3.0146 }\end{array}$ & $\begin{array}{l}\text { Complejo de } \\
\text { Golgi }\end{array}$ & $\begin{array}{l}\text { Organelo celular } \\
\text { del sistema } \\
\text { endomembranoso, } \\
\text { encargado de } \\
\text { empaquetar } \\
\text { proteínas, antes que } \\
\text { sean enviadas a su } \\
\text { destino }\end{array}$ & $\begin{array}{l}\text { Complexus, } \\
\text { [complecti] latín: } \\
\text { "enlazar" y epónimo } \\
\text { Golgi + [ensis] latín }\end{array}$ & $\begin{array}{l}\text { Apparatus } \\
\text { cisternae }\end{array}$ & $\begin{array}{l}\text { Aparato } \\
\text { cisternal }\end{array}$ & $\begin{array}{l}\text { Apparātum [adparāre] } \\
\text { latín: “disponer" y } \\
\text { [cisternae] latín: } \\
\text { "estanque subterráneo } \\
\text { o hundidos para el } \\
\text { almacenamiento de } \\
\text { agua". }\end{array}$ \\
\hline $\begin{array}{l}\text { Apparatus } \\
\text { golgiensis } \\
\text { H1.00.01.3.0146 }\end{array}$ & & & $\begin{array}{l}\text { Apparātum [adparāre] } \\
\text { latín: "disponer" y } \\
\text { epónimo Golgi + } \\
\text { [ensis] latín }\end{array}$ & & & \\
\hline
\end{tabular}

El término Exocrinocytus um granulis acidophilis proviene de "exocrino", adjetivo que se utiliza en el área de la fisiología y que se refiere al que secreta hacia fuera. Se aplica a las glándulas que vierten su secreción al tubo digestivo o al exterior del organismo, y por extensión, de dicha secreción. Del frances "exocrine" del griego [éxō $\ddot{\varepsilon} \xi \omega$, "por fuera" + krin- ( $\dot{\varepsilon} \varkappa) \varkappa \varrho i v \omega$ "segregar" o "separar" + -o/-a del español que hace al término un adjetivo], la lengua base del término es un neologismo griego del siglo XX, documentado en 1904,

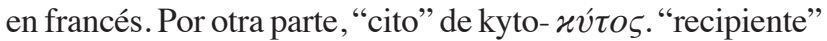
(sustantivo). El término "gránulo" es un palabra latina que deriva de grān(um) "grano" o "semilla" + dim. -ulu(m); y "acidófilo" es un adjetivo utilizado en histología que se refiere a una sustancia que se tiñe con colorantes ácidos, deriva del latín acidus, - $a$, -um adjetivo, "ácido" + griego

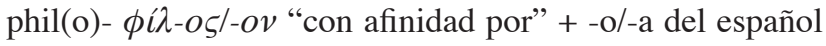
que hace al término un adjetivo, siendo un neologismo del siglo XX, documentada en 1900 en inglés (Cortés \& Ureña).

Según el análisis realizado, podemos observar que el término Cellula panethensis no sigue la sugerencias de la Terminología, ya que utiliza el epónimo Paneth en la construcción de la palabra panethensis. Respecto de Exocrinocytus granulis acidophilis, creemos que se podrían utilizar términos más descriptivos que den luces en relación a su función y ubicación. Así, proponemos el término Célula

Tabla III. Análisis del término Cellula panethensis o Exocrinocytus um granulis acidophilis presente en Terminologia Histologica y propuesta de un nuevo término latino.

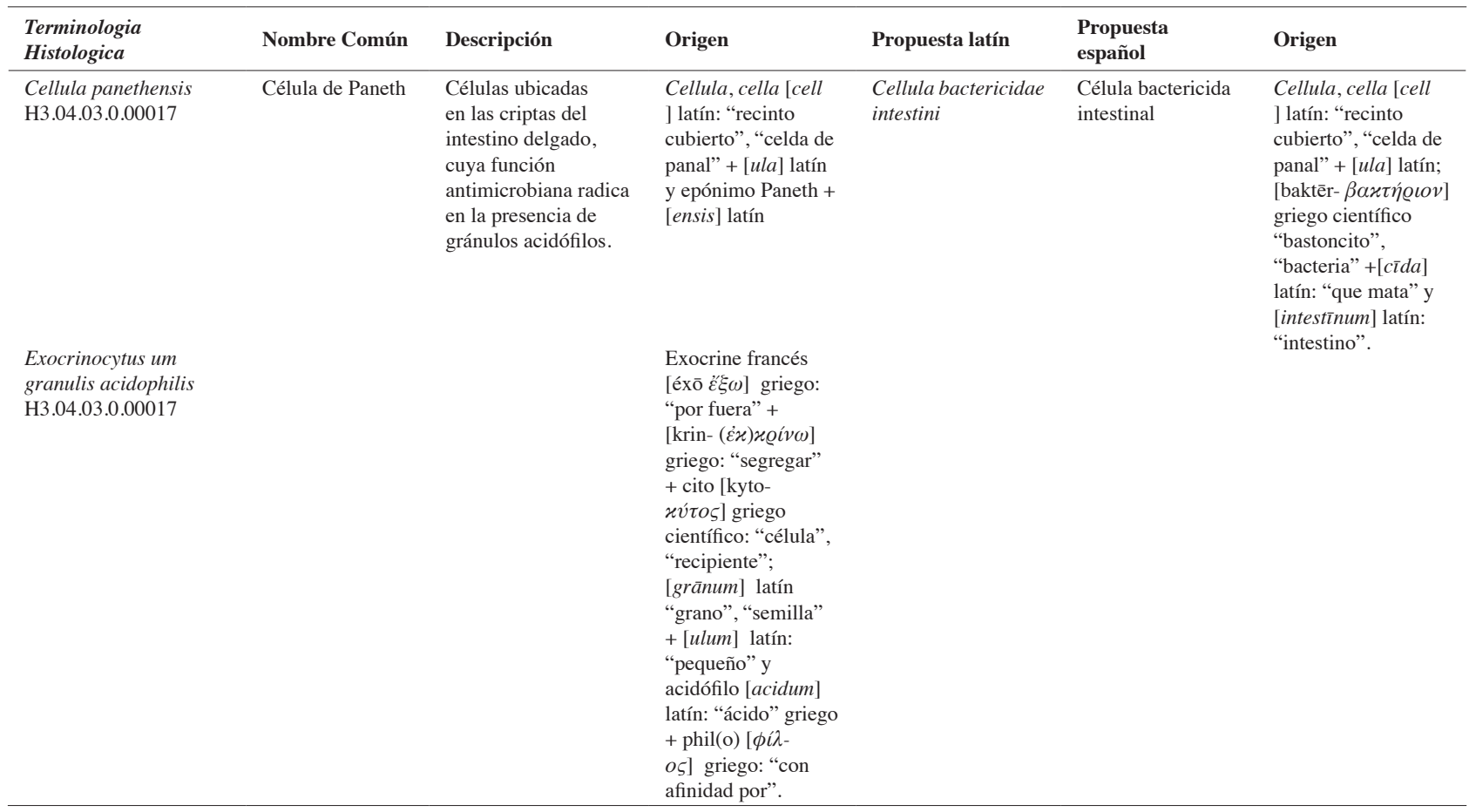


bactericida intestinal (Cellula bactericidae intestinalis), "bactericida" proviene del griego baktēr-i(o)- $\beta \alpha \varkappa \tau \eta ் \varrho-\iota o v$ "bastoncito", griego científico "bacteria" + latín -cīda "que mata", y es un neologismo del siglo XIX, documentado en 1884 en inglés, cuya lengua base es greco-latina, "intestinal" proviene del latín in-testīn(um) "intestino" + sufijo adjetival -alis, lengua base latín antiguo, desde latín arcaico intestīnu $(m)$ o en plural intestīna con el mismo significado. Se encuentra documentado en español desde 1450 (Cortés \& Ureña), (Tabla III).

\section{Neuron purkinjense}

Neurona es un término histológico, que hace alusión a la célula nerviosa, que generalmente consta de un cuerpo de forma variable y provisto de diversas prolongaciones, una de las cuales, de aspecto filiforme y más larga que las demás, es el axón. Neuron purkinjense proviene de las palabras "neuron" del griego neur(o)- veveov "nervio" y en griego científico "sistema nervioso" + - $n$ griego $+-a$ español. Es un neologismo acuñado en 1891 en alemán por H.W.G. Walde- yer (Cortés \& Ureña). El término "purkinjense" procede de Purkinje (epónimo) + sufijo-ense, adaptación del genitivo de tercera declinación -ensis.

Según el análisis realizado, podemos observar que el término Neuron purkinjense no sigue la sugerencias de la Terminología, ya que utiliza el epónimo Purkinje en la construcción de la palabra purkinjense. Así, proponemos el término Neurona cerebelar piriforme (Neuron cerebelaris piriformis), "neurona" proviene del griego neuron vev̂@ov "nervio" y en griego científico "sistema nervioso" + - $n$ griego + - a español; "cerebelar" < latín cerebellum, con un posterior cambio de significado; en latín clásico, cerebellu $(m)$ es "cerebro pequeño", sin embargo, este fue el término que eligieron traductores medievales de Galeno, para el griego "parenkephalís" $\pi \alpha \varrho \varepsilon \gamma \varkappa \varepsilon \phi \alpha \lambda i \varsigma^{\prime}$ "cerebelo". Se encuentra compuesta por el latín cerebrum "cerebro" + dim -ellu(m) + sufijo adjetival -aris (que alterna con -alis, según la forma fonética del lexema), y "piriforme" < latín Pirum(i) "pera"y formis $<$ forma + -is "que tiene forma de" (Cortés \& Ureña), (Tabla IV).

Tabla VI. Análisis del término Neuron purkinjense presente en Terminologia Histologica y propuesta de un nuevo término latino.

\begin{tabular}{|c|c|c|c|c|c|c|}
\hline $\begin{array}{l}\text { Terminologia } \\
\text { Histologica }\end{array}$ & $\begin{array}{l}\text { Nombre } \\
\text { Común }\end{array}$ & Descripción & Origen & $\begin{array}{l}\text { Propuesta } \\
\text { latín }\end{array}$ & $\begin{array}{l}\text { Propuesta } \\
\text { español }\end{array}$ & Origen \\
\hline $\begin{array}{l}\text { Neuron purkinjense } \\
\text { H3.11.03.4.01015 }\end{array}$ & $\begin{array}{l}\text { Neurona de } \\
\text { Purkinje }\end{array}$ & $\begin{array}{l}\text { Célula } \\
\text { GABAérgica } \\
\text { ubicada en la } \\
\text { corteza cerebelar }\end{array}$ & 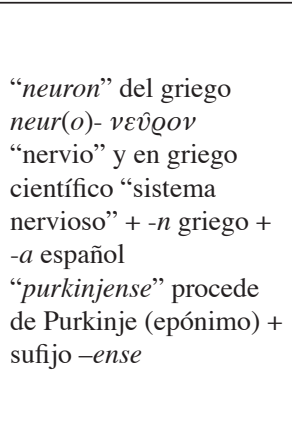 & $\begin{array}{l}\text { Neuron } \\
\text { cerebelaris } \\
\text { piriformis }\end{array}$ & $\begin{array}{l}\text { Neurona } \\
\text { cerebelar } \\
\text { piriforme }\end{array}$ & $\begin{array}{l}\text { "neuron" griego } \\
\text { neur(o)- vevooov } \\
\text { "nervio" y en } \\
\text { griego científico } \\
\text { "sistema nervioso" } \\
\text { + - } n \text { griego + -a } \\
\text { español; "cerebelar" } \\
<\text { latín cerebellum, } \\
\text { "cerebro pequeño", } \\
\text { y "piriforme" < latín } \\
\text { Pirum }(i) \text { "pera" y } \\
\text { formis < forma + -is } \\
\text { "que tiene forma de" }\end{array}$ \\
\hline
\end{tabular}

\section{DISCUSIÓN}

El latín es considerado, junto al griego, una de las lenguas fundadoras de las civilizaciones de Occidente por varias razones. En primer lugar, fue utilizado durante la época del poderío romano y con la extensión que éste tuvo por toda Europa. En segundo lugar, el latín fue la lengua indoeuropea de la cual surgieron muchas de las lenguas romances actuales como el italiano, el español, el portugués, el francés, entre otras. En tercer lugar, porque una vez caído el Imperio Romano, el latín siguió existiendo, no sólo en las ceremonias religiosas, sino también, en sectores intelectuales y científicos, tales como, en las descripciones de la Botánica y la Zoología y, hasta el día de hoy en los nombres científicos. Prueba de ello, en las ciencias morfológicas, es que las diferentes terminologías internacionales (Anatómica, Histológica y Embriológica) utilizan como base léxicos de origen greco-latino y el lenguaje empleado para su escritura es el latín (Kachlik et al., 2008).

Considerando lo anterior, para los profesionales de las distintas áreas de las ciencias médicas y para los morfólogos en particular, el conocimiento del latín y el griego ofrece ventajas relevantes, ya que permite realizar una adecuada interpretación y comunicación, tanto de la $T A, T H$ como $T E$ (Mejías Stuven; Vásquez \& del Sol, 2015). Por otra parte, las constantes actualizaciones realizadas a la terminología morfológica internacional (FICAT), así como las propuestas 
de nuevos términos para denominar estructuras de manera más detallada o porque simplemente no se encuentran presentes para describir una determinada estructura, hacen que cada vez más el conocimiento de lenguas clásicas sea necesario. Afortunadamente, el debate sobre la utilidad del latín y el griego en las ciencias morfológicas ha sido superado. Ejemplo de ello son los Simposios Ibero-Latinoamericanos de Terminología (SILAT), iniciados en el año 2009 por la Asociación Panamericana de Anatomía (APA), que tienen por misión divulgar la terminología morfológica internacional, para que las instituciones educativas de medicina y de otras áreas de la salud, de hablas hispana y portuguesa, la empleen cotidianamente (Losardo et al., 2010). Durante los SILAT trabajan conjuntamente investigadores de las ciencias morfológicas y expertos en lenguas clásicas, para revisar las diferentes terminologías internacionales con el propósito de evidenciar las discrepancias de algunos términos y unificar criterios.

Además de estas instancias, existen publicaciones en el ámbito terminológico que exponen la problemática de utilizar epónimos, la falta de precisión en la identificación de algunos términos, discrepancias entre $T A$ y $T H$, entre otras, con la finalidad de mejorar las diferentes terminologías internacionales (Olry, 2014a; Roa \& del Sol; Vásquez \& del Sol, 2014; 2015).

Bajo este contexto, hemos observado que algunos términos incluidos en $T H$ aún presentan nombres propios, en los cuales son honrados investigadores en el área celular e histológica como Theodor Schwann (Schwannocytus) y Camillo Golgi (Complexux golgiensis), el primero cofundador de la Teoría Celular y el segundo ganador del premio Nobel.Así como los términos; Cellula panethensis, referente al histólogo y fisiólogo austríaco Joseph Paneth y Neuron purkinjense, referente a Jan Evangelista Purkyně (Purkinje).

Algunas explicaciones a estos hechos tiene relación con que los epónimos están profundamente arraigados en la historia médica, la educación y el lenguaje (González-López; Fargen \& Hoh, 2014, Gest, 2014). En relación a la historia médica, los epónimos nos permiten celebrar los esfuerzos de investigadores incansables en sus descubrimientos críticos y dar personalidad a los términos que comunican. Sin embargo, han sido criticados por su inexactitud histórica, por rendir homenaje inmerecido a personas que no eran los primeros descubridores de las estructuras en cuestión o por ser redundantes o estar contaminados por ideologías políticas (Olry, 2014b; Vásquez \& del Sol, 2014). En el ámbito de la educación y formación médica, Martin et al. (2014), informaron que casi el $25 \%$ de los anatomistas pertenecientes a la American Association of Clinical Anatomists (AACA) no estaban familiarizados con el Comité Federativo de Termi- nología Anatómica (FCAT). Los datos demostraron que los anatomistas clínicos de la AACA no son consistentes en la forma en que utilizan la terminología anatómica, así como la forma en que se ajustan a la terminología anatómica, datos preocupantes sabiendo que casi el $40 \%$ de los encuestados eran autores de textos. Junto con lo anterior, podemos observar que los epónimos también se encuentran en términos de uso común, por lo cual su erradicación se dificulta aún más. Algunos ejemplos son "pasteurización" o "roentgenología", donde el nombre de descubridores o inventores se asocia con el significado de los epónimos, no mediante el genitivo, sino en forma de raíz, un ejemplo similar en el área médica es "bartholinitis" (inflamación de las glándulas vestibulares mayores descritos por Caspar Bartholin en 1677) o mediante adjetivos (facies hipocrática) (Benavent \& Iscla, 2001; Olry, 2014a).

Muchas veces los epónimos utilizados implican uno o dos apellidos vinculados y pueden ser más fáciles de comunicar que nombres científicas largos o difíciles, un ejemplo es la "Tetralogía de Fallot", que es mucho más fácil que "Enfermedad cardíaca congénita cianótica debido al defecto del tabique ventricular, con estenosis pulmonar, hipertrofia del ventrículo derecho y la aorta en dextroposición" (Woywodt \& Matteson, 2007). Además, algunos epónimos anatómicos no tienen contraparte oficial en latín, en tales casos, los epónimos son la mejor manera (y única) para evitar que los científicos constantemente acuñen nuevos nombres comunes (Olry, 2014a).

Por otra parte, proponer nuevos términos que estén más acorde con los señalado por la IFAA y la propia terminología, presenta grandes desafíos. Losardo et al. (2015) señalaron que un término no sólo es una palabra que hace referencia a una estructura morfológica propia de la medicina, sino que también, es una unidad del lenguaje, un vehículo de comunicación, un elemento cognitivo e informático. Así, el uso de los términos va más allá de las normas que un grupo de expertos quiera imponer al resto de la comunidad científica. Designar una denominación "oficial" y eliminar las demás variedades no significa que a partir de ese momento se adopte dicha norma, ya que el uso va siempre por delante de la norma y es difícil revertir la situación a corto plazo.

En atención a lo señalado, pretendemos con estos antecedentes iniciales entregar argumentos que permitan seguir unificando criterios y que ellos puedan ser considerados por los expertos que conforman el Programa Federativo Internacional de Terminología Anatómica y, como bien se señala, permitir el establecimiento de diálogo con los miembros de la Federación Internacional de Asociaciones de Anatomistas e ir mejorando la comunicación científica entre los diferentes actores de las ciencias morfológicas. 
ROA, I.; VÁSQUEZ, B. \& CONTRERAS, M. Persistence of eponyms in Terminologia Histologica. Int. J. Morphol., 34(4):1245$1252,2016$.

SUMMARY: Eponyms are still frequently used among clinicians and scholars to refer to the various structures in histology. Despite efforts by the morphological community to eradicate eponyms from medical language, nowadays they are practical, and even present in Terminologia Histologica (TH), such as in the case of Schannocytus (H2.00.06.2.02003) concerning the term Schwann cell; Complexus golgiensis (H1.00.01.3.0146) relating to the Golgi apparatus, Cellula panethensis (H3.04.03.0.00017) concerning the Paneth cell and Neuron purkinjense (H3.11.03.4.01015), the term Purkinje neuron which refers to researchers Theodor Schwann, Camillo Golgi, Joseph Paneth and Jan Evangelist Purkinje, respectively. The aim of this study was to conduct an analysis of these terms from a linguistic point of view and propose new Latin names, following guidelines established in the terminology wherein the names of structures must, have an informative value, be written in Latin as a base language, and eliminate the use of eponyms. The terms analyzed, refer to cells or organelles names frequently used, they have limited descriptive value, many with purely Greek roots and other neologisms, which names have endured over time in honor of renowned researchers. Using terms from Larin, we propose modifications with respect to classification and derivatives. In conclusion, we hope that with this introduction, the information to consolidate standards will be considered by the experts of the Federal International Committee on Anatomical Terminology and further, initiate a dialogue with International Federation of Associations of Anatomists members, while encouraging ongoing communication between the various players of morphological sciences.

KEY WORDS: Schannocytus; Schwann cell; Complexus golgiensis; Golgi apparatus; Cellula panethensis; Paneth cell; Neuron purkinjense; Purkinje neuron; Terminologia Histologica; Eponyms.

\section{REFERENCIAS BIBLIOGRÁFICAS}

Alberts, B.; Johnson, A.; Lewis, J.; Morgan, D.; Raff, M.; Roberts, K. \& Walter, P. Molecular Biology of the Cell. $6^{\text {th }}$ ed. New York, Garland Science, 2015.

Benavent, R. A. \& Iscla, A. A. Problemas del lenguaje médico actual (II): Abreviaciones y epónimos. Pap. Med., 10(4):1706, 2001.

Bhatheja, K. \& Field, J. Schwann cells: origins and role in axonal maintenance and regeneration. Int. J. Biochem. Cell Biol., 38(12):1995-9, 2006.

Bykov, V. L. Paneth cells: history of discovery, structural and functional characteristics and the role in the maintenance of homeostasis in the small intestine. Morfologiia, 145(1):6780,2014

Cortés Gabaudan, F. \& Ureña Bracero, J. Diccionario Médico-Biológico, Histórico y Etimológico. Salamanca, Ediciones Universidad de Salamanca, 2011. Disponible en: http://dicciomed. eusal.es, 2011 .

Cruz Gutiérrez, R.; Rodríguez Torres, A.; Prates, J. C.; Losardo, R. J. \& Valverde Barbato, N. Ibero-Latin-American Symposia Terminology. Anatomy, Histology and Embryology. Int. J. Morphol., 28(1):333-6, 2010.

Duque-Parra, J. E.; Llano-Idárraga, J. O. \& Duque-Parra, C. A. Reflections on eponyms in neuroscience terminology. Anat. Rec. B New Anat., 289(6):219-24, 2006.

Duque Parra, J.E.; Barco Ríos, J. \& Aguirre Cardona, V.E. From the terminology based on eponyms in surgery, to the international anatomical terminology: A great abyss that can be avoided. Int . J. Med.Surg. Sci., 1(3):253-6, 2014.

Fargen, K. M. \& Hoh, B. L. The debate over eponyms. Clin. Anat., 27(8):1137-40, 2014.

Federative International Comittee on Anatomical Terminology (FICAT). Terminologia Histologica, International Terms for Human Cytology and Histology. Philadelphia, Wolters Kluwer/ Lippincott Williams \& Wilkins, 2008.

Gest, T. R.Anatomical nomenclature and the use of eponyms. Clin. Anat., 27(8):1141, 2014.

Glare, P. G. W. Oxford Latin Dictionary. Londres, Oxford University Press/Clarendon Press, 1968.pp.347.

Goic, G.A. Sobre el uso de epónimos en medicina.Rev. Méd. Chile, 137(11):1508-10, 2009.

González-López, E. ¿Hay que seguir utilizando (algunos) epónimos médicos? Med.Clin. (Barc)., 134(15):703-4, 2010.

Jiménez-Gutiérrez, I. La sinonimia y la polisemia en la Terminología anatómica: Términos de ubicación y de relación de estructura anatómicas. Entreculturas, 1:579-97, 2009.

Kachlik, D.; Baca, V.; Bozdechova, I.; Cech, P. \& Musil, V. Anatomical terminology and nomenclature: past, present and highlights. Surg. Radiol. Anat., 30(6):459-66, 2008.

Kandel, E. R.; Schwartz, J. H. \& Jessell, T. M. Principios de Neurociencia. $4^{\text {ta }}$ ed. Madrid, Mc Graw-Hill/Interamericana, 2001. 
Kosinski, C. M. Theodor Schwann. Nervenarzt, 75(12):1248, 2004.

Losardo, R. J.; Cruz Gutiérrez, R.; Rodríguez Torres, A.; Prates, J. C. \& Valverde Barbato de Prates, N. Iberia-Latin-American Symposia of Morphological Terminology (SILAT). First two years and statute. Int. J. Morphol., 28(4):1323-6, 2010.

Losardo, R. J.; Valverde Barbato de Prates, N. E.; Arteaga-Martínez, M.; Cabral, R. H. \& García-Peláez, M. I. International Morphological Terminology: More than anatomy, histology and embryology. Int. J. Morphol., 33(1):400-7, 2015.

Martin, B. D.; Thorpe, D.; DeLuna, V.; Howard, T.; Hagemeyer, J. \& Wilkins, N. Frequency in usage of Terminologia Anatomica terms by clinical anatomists. J. Biomed.Educ., (2014):Article ID 950898, 2014.

Mazzarello, P.; Garbarino, C. \& Calligaro, A. How Camillo Golgi became "the Golgi". F. E. B. S. Lett., 583(23):3732-7, 2009.

Mejías Stuven, R. El Latín como lengua de la Terminología Anatómica: algunas observaciones sobre su rol. Rev. Argent. Anat. Onl., 3(2):33-42, 2012.

Olry, R. Anatomical eponyms, Part 1: To look on the bright side. Clin. Anat., 27(8):1142-4, 2014a.

Olry, R. Anatomical eponyms, Part 2: The other side of the coin. Clin. Anat., 27(8):1145-8, 2014b.

Noguera-Palau, J. J. Jan Evangelista Purkinje. Libochovice, 1787 - Praga, 1869. Arch. Soc. Esp. Oftalmol., 83(6):393-4, 2008.

Real Academia Española (RAE). Diccionario de la Lengua Española. Madrid, Real Academia Española, 2013. Disponible en: http://dle.rae.es/?id=A1JK3tM

Roa, I. \& del Sol, M. Clarification of Terminologia Embryologica: Gartner duct. Int. J. Med. Sug. Sci., 2(2):481-6, 2015.

Sango, K. \& Yamauchi, J. Schwann Cell Development and Pathology. Tokyo, Springer Japan, 2014.
Salgado, A. G. E. \& Trujillo, H. E. Terminología: Historia e importancia en el desarrollo de las ciencias morfológicas. F. $O$. P. J., 1(1):9-11, 2010.

Vásquez, B. \& del Sol, M. The Terminologia Histologica in the medical sciences. Int. J. Morphol., 32(1):375-80, 2014.

Vásquez, B. \& del Sol, M. Terminologia Anatomica and Terminologia Histologica. A meeting point between morphologists. Int. J. Morphol., 33(4):1585-90, 2015.

Whitworth, J. A. Should eponyms be abandoned? No. B. M. J., 335(7617):425, 2007.

Woywodt, A. \& Matteson, E. Should eponyms be abandoned? Yes. B. M.J., 335(7617):424, 2007.

Zhang, Z.\& Liu,Z. Paneth cells: the hub for sensing and regulating intestinal flora. Sci. China Life Sci., 59(5):463-7, 2016.

Dirección para Correspondencia:

Dr. Ignacio Roa Henríquez

Unidad de Morfología

Departamento de Ciencias Básicas Biomédicas

Facultad de Ciencias de la Salud

Universidad de Talca

Av. Lircay s/n

Talca

CHILE

E-mail: iroa@utalca.cl

Recibido : 11-06-2016

Aceptado: 14-08-2016 